\title{
Phenomenon of impact of audio-visual media texts with violent content: socio-pedagogical discourse
}

\author{
Olga Gorbatkova ${ }^{1 *}$, Marina Puylova ${ }^{2}$, and Susanna Nalesnaya $^{2}$ \\ ${ }^{1}$ Don State Technical University, 344002, Rostov-on-Don, Russia \\ ${ }^{2}$ Rostov State University of Economics (RINH), 344002, Rostov-on-Don, Russia
}

\begin{abstract}
In this article, the authors have carried out a hermeneutic analysis of the problem of violence among adolescents in audio-visual media texts and the peculiarities of this violent content impact. The material of the study is movies, TV programs, electronic versions of media texts reflecting the content of the violent segment in the adolescent environment. The main method is the hermeneutic analysis of discourse, which is based on the methodology created by A. Silverblatt and U. Eco. A hermeneutic analysis of audio-visual media texts with violent content showed that: - violence in different media texts differs in its peculiarities of expression, but at the same time, it is similar in social issues, methods and means of expressiveness, a tragic component in the narrative and image content; - the worldview of the audio-visual media texts authors is reduced to the position of fixing different types of violence; - a specific feature of the media products is the connection to the real life situation; - the value dominants of the main characters - adolescents (aggressors) are aggression, cruelty, etc.; - reasons for committing violent actions: conflict situations in the group, with people of different age and status; unrequited love; desire to raise the credibility, etc.
\end{abstract}

\section{Introduction}

Recently, the importance of studying the problem of violence among adolescents in the context of the Russian audio-visual media texts functioning and the specifics of the impact of social reality constructed by them through the prism of certain images of violent content is determined by: the process of massification in the media space, which is expressed in the acquisition of a quantitative and qualitative component as an integral segment in the focus of the media sphere; the tendency for actualization of discourse practices in the focus of the scientific and research space at the international level in the scope of the "violence" concept study in the media and its impact on the modern adolescents; the necessity to justify the peculiarities of formation of the objective reality representations, changes in the image of the world, the transmission of the aggressive behavior model on the part of the younger generation, which is formed under the effect of the information flow of aggressive content.

\footnotetext{
*Corresponding author: gorbatkova1987@bk.ru
} 
Today, the reflection of violence among adolescents in audio-visual media texts is one of the topical problems of the theoretical and practical segment of the research field not only of Russian, but also of foreign scientists.

In Russia, the problem of violence in the media has been realized relatively recently. Only from the late 1990 -s to the early 2000-s, the scientific works began to appear reflecting the attempts to study the concept of "violence" to some extent and identify the level of its impact on the younger generation. In its turn, foreign studies to a greater extent allow a deeper understanding of the psychological components, finding evidence that violence in the media increases the probability of aggressive and violent behavior, both in the short and long term, understanding the reasons and factors, conditions that contribute to an increase in the level of aggression and violence under the effect of violence images in the media.

However, the conducted analytical study allows us to assert that domestic and foreign studies do not cover the features of the violence expression among adolescents in different types of media channels and textual forms, the specifics of their reflection in the media, do not review the context in the field of scientific research that reveals the potential media education as one of the effective measures to fight the imitation of models of violence broadcast by various media channels in order to develop the media competence of the younger generation.

Moreover, it was revealed that there is a lack of scientific research concerning the following: a clear understanding of the concept of "violence", "media violence"; the specifics of personality traits of participants in a situation of violence among adolescents (victim, aggressor); effective measures to prevent and fight violence and violent behavior among adolescents.

The study for the first time attempts to carry out a hermeneutic analysis of the problem of violence among adolescents in the reflection of the modern Russian media, reveals the importance of the subject of violence in the media audio-visual content; the historical, world outlook, socio-cultural ideological context is revealed, the definition of the concept of "media violence among adolescents" is developed.

The purpose of our research consists in the following: to carry out a hermeneutic analysis of audio-visual media texts in Russia reflecting the violent content and the peculiarities of its impact on the younger generation.

\section{Materials and Methods}

The material of our research is contemporary Russian audio-visual media texts reflecting the content of the violent segment in the adolescent environment. The fundamental basis is made up of the media texts on the teenage violence: Russian movies ("Girls", 2005; "Corrections Class", 2014; "8.14”, 2015; "Lilja 4-ever", 2002; "School”, 2010; "Everybody Dies but Me", 2008; "Acid", 2018; "The Teacher", 2015; “The Hope Factory", 2014; "The Student", 2016 and others); the content of TV programs ("Let Them Talk", "Male / Female", "Duty part"); Internet versions of the media (RossiyskayaGazeta, Interfax, NEWS.ru, RIA Novosti, Komsomolskaya Pravda, MoskovskyKomsomolets (MK)).

The main research method was the hermeneutic analysis of discourse, which was based on the methodology created by A. Silverblatt [1], U. Eco [2]. The hermeneutic analysis within the framework of our research involves the interpretation of audio-visual media texts with violent content among adolescents in the focus of studying the historical, sociocultural, ideological context, structural components and narrative methods in order to reveal the deep meaning.

The auxiliary methods were: socio-cultural analysis, theoretical analysis of the scientific and research literature pool in the scope of the problem under consideration. 


\section{Results}

As part of our study we have carried out the hermeneutic analysis of the content of modern audio-visual media texts containing the images of violence among adolescents to identify the peculiarities of media violence expression and impact on the younger generation, namely: movies, TV programs, mass media texts of $1992-2021$ period.

Thus, based on some movies of modern Russian cinematography (for example, "Girls", 2005; "Corrections Class", 2014; "8.14", 2015; "Lilja 4-ever", 2002; "School", 2010; "Everybody Dies but Me", 2008; "Acid", 2018; "The Teacher", 2015; "The Hope Factory", 2014; "The Student", 2016 and etc.) we have attempted to perform the hermeneutical analysis of the "violence" concept in the mirror of cinematography allowing to formulate a number of conclusions.

We have managed to reveal that the images of violence in motion pictures to a greater extent convey the model of behavior to the younger generation

At the same time, in the Soviet period, after the censorship abolition in the media space, the episodes of violent content began to be actively broadcast (practically without observing the officially accepted age restrictions), however, already in the post-Soviet period, the content of films formed the image of violence among adolescents as a priority in the main character's role.

Speaking about the world view aspect of the author's message, the movie maker's position is reduced to one thing - getting a cinematic product based on the violence among adolescents in its various manifestations.

The stereotypical image recreated by the media text authors is quite remarkable, which can be summarized by the following constants: - there is a stereotyped plot line (introduction, development of events, culmination, apotheosis; scene of action, system of values, behavioral reactions); - the presence of both verbal (the linguistic originality of the characters' speech) and non-verbal stereotypes (description in movies with scenes of teenage violence between teenagers, expression of cruelty, aggression, attacks on teachers, peers, demonstration of the lifestyle and behavior patterns of adolescents).

In movies among the characters-teenagers there are leaders, heroes demonstrating the conformism; adolescents who have difficulties in adapting to the ongoing changes in the world around them); extroverts and introverts.

In many cases, in movies, the "victim" characters always react violently to the violence against them, therefore the boundaries between the position of a "victim" and a "violator" are unclear; perhaps the media text authors create an ambiguous image in an attempt to recreate the scenario of events most attractive to the young audience and possible in reality.

As a rule, in most cases, physical appearance is the main reason of violence expression in various forms. Violent acts are carried out against both boys and girls, but there are differences between the sexes.

It has to be said that today not only cinema acts as a tool for broadcasting the image of violence among adolescents, but also other media.

Undoubtedly, TV programs, electronic mass media focus on important and significant events related to the expression of violence among adolescents, sometimes acting as a kind of a mechanism in the formation of behavior certain model for the younger generation.

Information about dramatic events between the young persons is instantly reflected in the news of the leading Russian TV channels (Channel One Russia, Russia, NTV, Channel Five, REN TV, Mir and others).

The analysis of the TV programs' content shows that the media material content devoted to the problem of violence among adolescents, not only against peers, but also against adults, is characterized by the aggression and cruelty level increase; if TV programs broadcast since 2000 are characterized by such segments as: beating with hands, feet, 
bullying at school, cyber-bullying, then since 2014 the content itself has changed its "inner content", expressed by such signs as: armed attack, teacher attack with an ax, a knife, mass execution, etc.

Thus, in our opinion, recently the mass media has been penetrating tightly into the political and economic system playing the role of a powerful tool in influencing the consciousness of a person and a group of people, forming the portrait of the world.

The facts about the occurred expressions of violence of adolescents against peers / adults, as a rule, receive a wide resonance in printed / online mass media and cause heated discussions about the necessity to take the preventive measures, about the impact of the media space (cinema, TV shows, press, Internet, etc.) having the content of violent nature.

In our opinion, this circumstance is determined by the growth of cases of armed attacks by adolescents on their peers and teachers. In the result of electronic media content analysis, we managed to make a chronology and trace the dynamics of attacks by adolescents in Russian schools (Table 1).

Table 1. Chronology of cases of adolescent attacks in Russian schools in 2013 - 2021

\begin{tabular}{|c|c|l|}
\hline Year & Number of attacks & Instrument of crime \\
\hline 2013 & 3 & Fire arms \\
\hline 2014 & 7 & Fire arms \\
\hline 2015 & 5 & Fire arms \\
\hline 2016 & 2 & Fire arms \\
\hline 2017 & 8 & Fire arms, knife \\
\hline 2018 & 12 & Fire arms, knife, axe \\
\hline 2019 & 7 & $\begin{array}{l}\text { Fire arms, knife, axe, home- } \\
\text { made explosives, } \\
\text { firecrackers, Molotov cocktail }\end{array}$ \\
\hline 2020 & 2 & $\begin{array}{l}\text { Fire arms, knife, axe, home- } \\
\text { made explosives, } \\
\text { firecrackers, Molotov cocktail }\end{array}$ \\
\hline 2021 & 1 & $\begin{array}{l}\text { Fire arms, home-made } \\
\text { explosives, firecrackers }\end{array}$ \\
\hline
\end{tabular}

Thus, it should be noted that in 2018 the maximum number of crimes committed by adolescents against their peers, students and teachers was recorded. The following instruments of crime were predominant: fire arms, knife, axe, home-made explosives, Molotov cocktail, firecrackers, torches. The range of instruments of crime has expanded over the years.

Analysis of electronic texts of mass media about the expression of various forms of violence among the adolescents shows that the majority of messages were accompanied by the actual names and surnames of the participants of the tragic events that took place, photos or videos with episodes, as well as a detailed description, a clear plan of attack and the sequence of events. In our opinion, such coverage of events, on the one hand, speaks about the unethical coverage of the topic of violence, and on the other hand, it can only awaken the interest of the younger generation to this type of phenomenon. Of course, there is a certain risk of promoting aggressive actions.

The major part of the selected articles was the episodic reports, while the message was informative. Moreover, since 2018 there has been a tendency of increased attention to the development and introduction of measures preventing the violence among adolescents, especially in schools, in particular, strengthening of the school activities in the direction of preventive work with adolescents; expanding the use of the mass media for preventive 
purposes to prevent children involvement in destructive / criminal activities; monitoring of social networks; increase of efforts in the law context.

It should be emphasized that the worldview of the media text authors is reduced to the position of documenting violence, cruel scenes occurring among adolescents. At the same time, the genre spectrum was determined by reports, interviews, notes and chronicle messages. The authors identified such leading types of violence among adolescents in the scope of the studied material as bullying, cyber-bullying, school shooting, mobbing, while physical and psychological (emotional) violence dominated.

Together with this we should add that the system of values was determined by such dominants as: anger, hatred, ruthlessness, aggression, ferocity, merciless cruelty.

It is characteristic that the reasons for violent actions expression are determined by the presence of conflict situations in a group of adolescents, in relations with adults (teachers, parents, etc.), unrequited love, desire to raise the credibility in the group.

Thus, the essence of the above is reduced to the fact that in modern Russian audiovisual media texts one can observe: hundreds of evidences of violent actions by the young persons against their peers and adults; assumptions or facts about the juvenile criminals motivation are one of the foundations of media texts about violence; non-compliance with the legal and ethical standards when configuring a media product.

It seems that within the framework of the studied problem it is especially valuable to emphasize that today the Internet is a powerful force, which is characterized by the constant availability of various media sources (cinema, television, press, etc.), actively reflecting violence in adolescence, thereby creating a certain degree of all conditions for the accessibility of multimedia content with violent content.

A significant part of the media content is clearly aggressive, as a result of which there is a direct impact on the psyche, beliefs and, in general, on the people behavior in the society.

\section{Discussion}

The analysis of the available scientific research on the subject under consideration allows us to assert that the problem of violence among adolescents has been investigated fragmentarily, while we were unable to find a comprehensive, in-depth analysis both in the works of the Russian and foreign scientists.

It is important to emphasize that in Russia the problem of violence in the media has been realized relatively recently. In the Soviet period there were no scientific studies in the context of analyzing the peculiarities of the scenes of violence influence on the audience and only in the period from the late 1990s to the early 2000s the active interest from the Russian researchers has been shown. In this period the scientific works reflecting the attempts to study the concept of "school violence" to a greater or lesser extent and identify the level of its impact on the younger generation have appeared $[1 ; 3 ; 4 ; 5 ; 6 ; 7]$.

At the same time, studies of many foreign scientists are devoted to the problem of aggressive behavior, bullying in the educational environment, for example, L.E. Walker, D. Shapiro and S. Akl [8], J.S. Cawood and M.H. Corcoran [9], G.D. Gottfredson, D.C. Gottfredson [10], E. Cantone [11], M.J. Elinoff, S.M. Chafouleas, K.A. Sassu [12], J. Page, J.A. Daniels, S.J. Craig [13], R. Borum, D. Cornell, W. Modzeleski[14], N.S. Dahmen[15].

Speaking about the subject of violence in the media texts, it is important to emphasize that in this segment, there is still no clear understanding of what "media violence" is.

So, when analyzing the concept of "media violence", it is important to focus on the fact that in many scientific works it is considered in correlation with the concepts of "aggression and violence". In this regard, the disclosure of the "media violence" concept in our study will largely be carried out through the prism of these terms. It is highly relevant in this context to emphasize that today there are many definitions of the concept of "aggression", 
which determines the presence of a certain kind of inaccuracies and ambiguities in the process of understanding the essence of this term and determining its basic characteristics in the course of expression in real life by an individual.

Thus, American psychologists Robert Baron and Deborah Richardson [16] note that there are several conclusions regarding the definition of "aggression" and "violence" concepts' essence. One more definition was proposed by the American researcher in the field of social psychology L. Berkowitz, according to which the actions can be considered as aggressive only if they include intentions of offence or insult, and not just lead to such consequences [17]. In addition, we were able to find another point of view in the focus of the segment under consideration, which reduces to the fact that the term "aggression" is determined only by deciphering the infliction of physical injury and damage.

In addition to that, Richard Harris argues that the term "violence" is understood as causing an intentional physical harm to another person. "Aggressive motives are always hidden behind the cruelty of behavior. When we watch TV, we observe acts of direct violence and see their aggressive essence" [18].

M.A. Nikulina, Yu.S. Burko point of view revealing the essence of the "media violence" concept is quite interesting in the field of our study, the authors focus on the psychological content of the degree of impact noting the following: "Media violence is a psychological impact on consciousness through printed, television, video and audio production, directly or indirectly leading to a change in social behavior, opinions about the surrounding reality and, in a number of certain cases, stimulating a person to take action" [19].

Well-known American researchers J. Bryant and S. Thompson in their work "The Impact of Media Violence" note that "one of the most pressing social problems of our time has been and remains the negative impact of media violence on the consumer of information. Public concern about this is due in large part to the content of feature films and cartoons, as well as violent video games and Internet websites" [20].

Thus, as a result of an analytical study of the theoretical block of the studied problem, based on the views of the professional community, a definition of the "media violence among adolescents" concept was developed denoting the expression of behavior in the media, which includes the victimization of children and adults, the commission of crimes by the young people, physical and psychological exploitation, bullying, fights, riots that cause physical and mental harm, injury to people of different age groups, cyber victimization, cyber threats, violation of the boundaries of the sexual nature, as well as the use of weapons using media channels and media technologies.

Meanwhile, foreign research allows to a greater extent (J. Bryant, S. Thompson, B. Krahé, R. Baron, D. Richardson, R. Harris) a deeper understanding of the psychological components, to find evidence that violence in the media increases the probability of aggressive and violent behavior, both in the short and in the long-term perspective, to understand the causes and factors, conditions that contribute to an increase in the level of aggression and violence under the effect of images of violence in the media.

Together with that, some American scientists A. Bandura [21], L. Berkowitz [22], B.J. Bushman \& R.G. Geen[23], as well as Russian scientists A.V. Fedorov [24], S.V. Knizhnikova [25], O.S. Klyuchevskaya [26], V.F. Martyushov, A.S. Lomakin, V.V. Borovik [27] performed the research of the media violence effect and the correlation between the violence in the media and the level of aggression among the audience in real life conditions.

The whole range of scientific and research works devoted to the study of the impact of Russian media broadcasting violence in different variations on the audience can be conventionally divided into several groups:

a) Scientific content reflecting: 
- study of the peculiarities of the demonstration of scenes of violence on the Russian screens;

- researches that formulate theses about the negative psychological and moral impact of scenes of violence on the audience;

- the results of sociological researches concerning the frequency and nature of scenes of violence shown on the Russian screens.

b) Scientific works reflecting:

- researches that formulate provisions on the impact of printed / electronic media texts on the audience as a colossal threat to the psychological and information security of the individual and the information society;

- researches reflecting the verbal and non-verbal violence in the media texts, news reports (emergency or crisis), TV programs, media impact on the audience.

Let us note that modern studies in the field of the influence of scenes of aggression images in audio-visual / printed media texts fully confirm the assumption that violent content in the media contributes to the strengthening of the tendency for the expression of aggressive behavior in the society. As a rule, domestic researchers did not focus on the features of the media violence expression in various media texts.

Thus, several approaches to the mechanisms of media influence can be found in the scientific and research field of the analysis of the problem related to the media images of violence influence on the intensification of aggressive expressions in the society by the adolescent audience: first, increased excitement due to the observation of scenes of violence in the media; second, activation of thoughts and feelings of an aggressive nature (priming); third, the development of new types of aggressive reactions; fourth, weakening the prohibitions on aggression; fifth, reduced sensitivity to the victims' suffering; sixth, the formation of the viewer's idea of reality.

Thus, in the course of our research, we were able to determine a close relationship between the concepts of "violence", "media violence", "aggression".

At the same time, verbal and non-verbal expressions are observed regardless of the type of media text containing the violent content. Thus, the concept of "media impact" is fundamental for the study of media violence as a social and psychological phenomenon.

\section{Conclusions}

The results of our analysis allow us drawing a number of particular conclusions that are of interest for our study:

1. Today the demonstration of various forms of violence in audio-visual media texts is sporadic. The specific character of the media violence phenomenon lies in the quantitative and qualitative reference of the media space, determined by the process of massification. At the same time, the infiltration of media violence into various spheres of life is carried out due to the determination by the media convergence processes - the fusion of texts, formats and practices into the conversational media space.

2. The analysis of the theoretical block in the context of the problem of violence in audiovisual media texts and the degree of their impact on the adolescent audience showed the problematic nature of the concept of "violence" and "media violence". At the same time, in our study we relied on the following definition of the concept of "media violence among adolescents" - it is an expression of behavior in the media, which includes the victimization of children and adults, the commission of crimes by the young people, physical and psychological exploitation, bullying, fights, riots that bring physical and mental harm, injury to adolescents / adults, cyber-victimization, cyber threats, violation of the boundaries of the sexual nature, as well as the use of weapons among adolescents using the media channels and media technologies. 
3. The phenomenon of "media impact" is a key phenomenon in the process of researching the problem of media violence. Numerous studies suggest a significant effect of media violence and the correlation between violence in audio-visual / printed media texts and the degree of aggressive behavior in real social reality among the audience.

The nature of the media influence determines the peculiarities in the dependences between the degree of violence expression in the media and aggressive moods in the society.

4. A significant role in understanding the features of the violence expression in the media was played by the hermeneutic analysis of modern Russian audio-visual media texts with violent content among adolescents, which showed that: - the overwhelming majority of media texts was based on the standards that to a significant extent reflected the important changes occurring in the political, socio-historical, cultural context; - violence in different media texts differs in the features of its expression, but at the same time, it is similar in social issues, techniques and means of expressiveness, the tragic component in the narrative content and the image; - the worldview of the authors of audio-visual and printed / electronic texts is reduced to the position of fixing various forms of violence, cruel, bloody scenes. The main result of the author's position is a product in the form of audio-visual and printed / electronic text, containing a naturalistic display of scenes of violent content in its various expression forms; - a specific feature of the media products reflecting the violent content - connection with the real world situation; - value dominants of the main characters - adolescents (aggressors) of audio-visual and printed / electronic texts - anger, hatred, ruthlessness, aggression, merciless cruelty; - the range of reasons for committing the violent actions is determined by the occurrence of conflict situations in the group, in relations with peers / adolescents, different categories of people, unrequited love, the desire to raise credibility in the peer group.

Therefore, modern Russian audio-visual media texts represent aggression and cruelty, attacks and murders, as a rule, broadcasting a detailed description of the events that have occurred to the public, while reflecting not only in the consciousness of a person, especially the younger generation, but also influencing the behavior, the system of attitudes towards surrounding reality.

We dare to assert that today the problem of violence among adolescents in the mirror of the media takes a socially significant position requiring a solution not only at the practical level, but also at the level of scientific comprehension.

It seems that it is necessary to move in this direction when identifying the social effects of aggressive information in the media content.

And although, as the analysis has shown, there are a number of segments that require indepth research, however, most Russian scientists still agree on one thing: violence in the media is a huge evil that causes significant harm to humans.

\section{References}

1. A. Silverblatt, Media Literacy (Westport, Connecticut - London, Praeger, 2001).

2. U. Eko, The role of a reader (Research on the text semiotics, Symposium, SaintPetersburg, 2005).

3. O.V. Bashkatov, Violence as a socio-cultural phenomenon (PhD. Dis. Saratov State Technical University, Saratov, 2001).

4. E.N. Volkova, A.V. Grishina, Psychological Science and Education 6, 19-29 (2013).

5. L.V. Potapova, Tavrichesky Scientific Observer 6 (11), 47-54 (2016).

6. K.A. Tarasov, Publishing House of the Research Institute of Cinematography, Moscow (2000).

7. K.A. Tarasov, Communicology 5 (2), 168-180 (2017). 
8. L.E. Walker, D. Shapiro, S. Akl, School violence introduction to forensic psychology, 277-290 (2020). DOI: 10.1007/978-3-030-44470-9_19

9. J.S. Cawood, M.H. Corcoran, Violence assessment and intervention: The practitioner's handbook (New York, Routledge, 2019). DOI: 10.4324/9780429344367-9

10. G.D. Gottfredson, D.C. Gottfredson, The Cambridge Handbook of Violent Behavior and Aggression. Publisher: Cambridge University Press (2018). DOI: 10.1017/9781316847992.031

11. E. Cantone, A.P. Piras, M. Vellante, A. Preti, S. Danielsdottir, E. D’Aloja, D. Bhugra, Clinical Practice and Epidemiology in Mental Health 11, 58-76 (2015). DOI: $10.2174 / 1745017901511010058$

12. M.J. Elinoff, S.M. Chafouleas, K.A. Sassu, Psychology in the Schools 41 (8): 887 897 (2004). DOI: 10.1002/pits.20045

13. J. Page, J.A. Daniels, S.J. Craig, Violence in schools, 9-18, Springer, New York (2015). DOI: 10.1007/978-3-319-13912-8_2

14. R. Borum, D. Cornell, W. Modzeleski, S.R. Jimerson, A Review of the Evidence Educational Researcher 39 (1), 27-37 (2010). DOI: 10.3102/0013189X09357620

15. N.S. Dahmen, American Behavioral Scientist 62 (2), 163-180 (2018). DOI: 10.1177/0002764218756921

16. R. Baron, D. Richardson, Aggression (Saint-Petersburg, 2001).

17. L. Berkowitz, Aggression: reasons, consequences, control: the world's best textbook on the psychology of aggression (Prime-Evroznak, Saint-Petersburg, 2007).

18. R. Harris, Psychology of mass communications (Prime-Evroznak, Saint-Petersburg, 2003).

19. M.A. Nikulina, Yu.S. Burko, Almanac of modern science and education 4 (23), 117120 (2009).

20. J. Bryant, S. Thompson, Fundamentals of media effects (Publishing house "Williams", Moscow, 2004).

21. A. Bandura, Aggression: A social learning analysis (NJ, Prentice-Hall, Englewood Cliffs, 1973).

22. L. Berkowitz, Psychological Bulletin 95, 410-427 (1989).

23. B.J. Bushman, R.G. Geen, Journal of Personality and Social Psychology 40, 687-700 (1990).

24. A.V. Fedorov, Children's rights and problem of violence on the Russian screen (Kuchma, Taganrog, 2004).

25. S.V. Knizhnikova, Social pedagogics 6, 107-115 (2014).

26. O.S. Kluchevskaya, Issues of journalism, pedagogy, linguistics 39 (3), 331-344 (2020). DOI: 10.18413/2712-7451-2020-39-3-331-344

27. V.F. Martushov, A.S. Lomakin, V.V. Borovik, TvSU Bulletin 4, 126-131 (2020). DOI: $10.26456 /$ vtphilos/2020.4.126 